
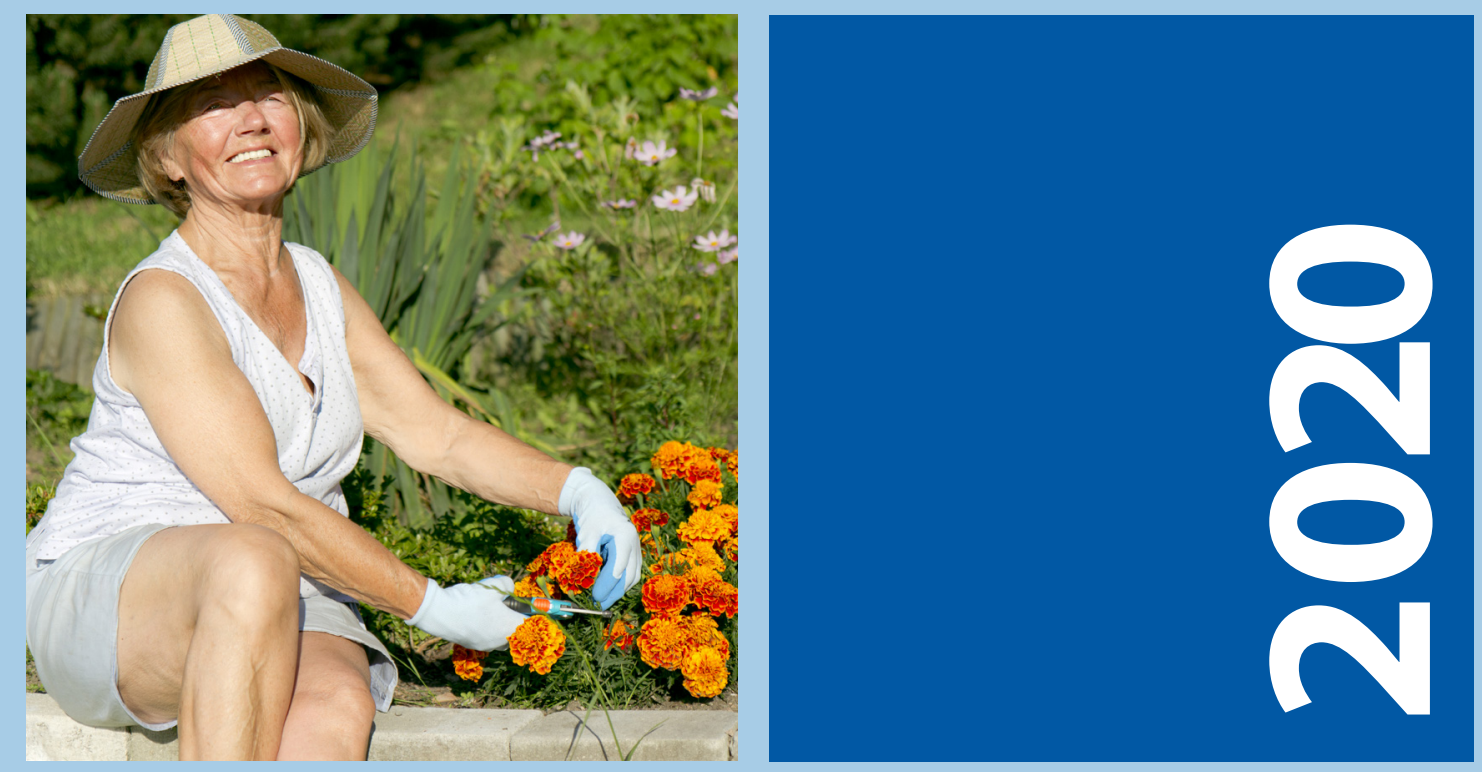

Vitamin D deficiency in Ireland - implications for COVID-19. Results from the Irish Longitudinal Study on Ageing (TILDA)

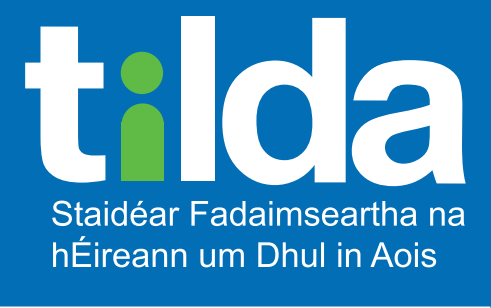

The Irish Longitudinal Study on Ageing 


\section{Vitamin D deficiency in Ireland - implications for COVID-19. Results from the Irish Longitudinal Study on Ageing (TILDA)}

Eamon Laird \& Rose Anne Kenny

The Irish Longitudinal Study on Ageing

On behalf of the TILDA team

April 2020 
Copyright (C) The Irish Longitudinal Study on Ageing 2020

The Irish Longitudinal Study on Ageing

Trinity College Dublin

Dublin 2

Tel: +35318962509

Email: tilda@tcd.ie

Website: www.tilda.ie

ISBN: 978-1-907894-30-5

https://www.doi.org/10.38018/TildaRe.2020-05 


\section{Acknowledgements}

We would like to acknowledge the vision and commitment of our study funders, the Department of Health, the Health Research Board, Science Foundation Ireland, The Atlantic Philanthropies, and Irish Life plc. We would like to state that any views expressed in this report are not necessarily those of the Department of Health or of the Minister for Health. We would also like to thank the TILDA participants without whom this research would not be possible. 


\section{Contents}

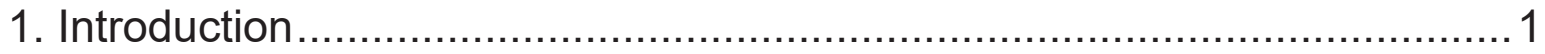

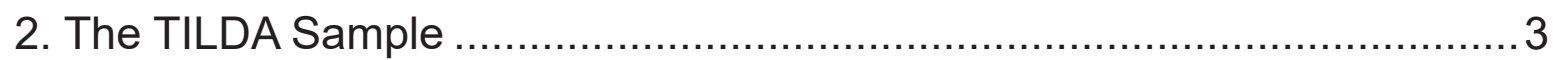

3. Vitamin D Status of Older Adults in Ireland in Winter ........................... 5

4. Vitamin D Status of Older Adults in Ireland in Summer ......................... 11

5. Vitamin D Status by Obesity and Respiratory Lung Conditions .............. 18

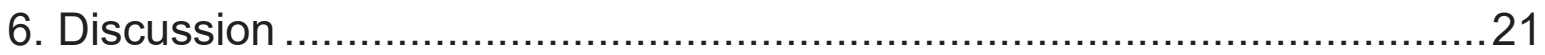

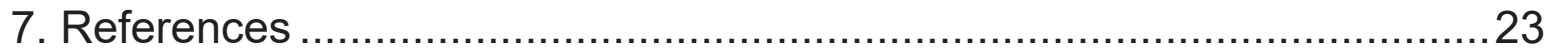

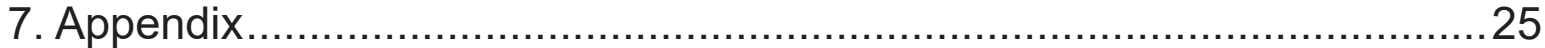




\section{tilda Staidéar Fadaimseartha $\mathrm{n}$ hÉireann um Dhul in Aois \\ The Irish Longitudinal Study on Ageing \\ VITAMIN D DEFICIENCY IN IRELAND - IMPLICATIONS FOR IMMUNE
PROTECTION FOR COVID-19}

WHY IS VITAMIN D IMPORTANT?

ESSENTIAL FOR BONE AND MUSCLE HEALTH

MAY HELP TO PREVENT RESPIRATORY

INFECTIONS

BENEFITS IMMUNE FUNCTION AND COUNTERS INFLAMMATION

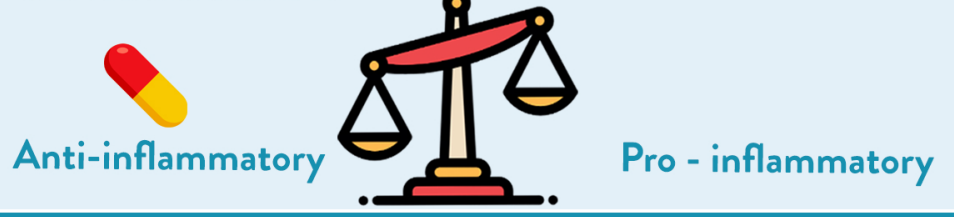

WHAT ARE THE RATES OF DEFICIENCY?

$1108 \%$ older adults in Ireland are deficient $=149,000$ adults

$120 \%$ older adults in Ireland are deficient in winter $=244,200$ adults

Almost $\%$ of those over 85 are deficient

1 in 2

1 in 4 in winter $=31,500$ adults

of the over 70s 'cocooning' are likely to be deficient $=115,500$ adults
WHO IS AT RISK OF DEFICIENCY?

THOSE WHO DON'T GET ENOUGH...
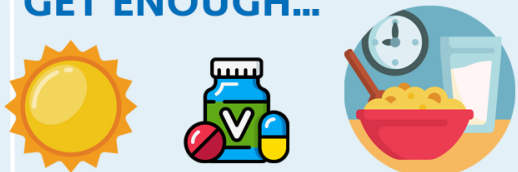

HOUSEBOUND

PEOPLE WITH

CHRONIC

DISEASE AND LUNG CONDITIONS
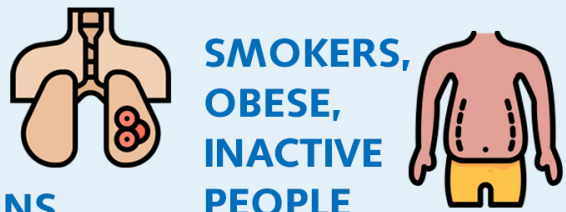

WHERE IS IT FOUND?

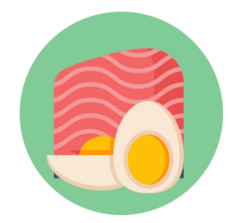

IN RICH FOOD SOURCES LIKE OILY FISH, EGGS, LIVER, AND FORTIFIED FOODS

VITAMIN D CAN BE PRODUCED FROM 10-15 MINUTES OF SUN EXPOSURE FROM LATE MARCH TO LATE SEPTEMBER

HOW MUCH VITAMIN D SHOULD BE TAKEN TO PREVENT DEFICIENCY?

- 10 UG (400 IU) IS THE MINIMUM RECOMMENDED DAILY INTAKE DURING THE WINTER TIME

- BETWEEN 15 - 20UG (600-800 IU/DAY). IU/DAY) IS RECOMMENDED FOR MOST AT-RISK GROUPS

For more information please visit www.tilda.ie Supported by $\begin{aligned} & \text { An Roinn Sláinte } \\ & \text { Department of Health }\end{aligned}$ 


\section{Key Messages}

\section{Why is Vitamin D important?}

- Vitamin $\mathrm{D}$ is essential for bone and muscle health

- Vitamin D may help prevent respiratory infections in those who have low vitamin $D$ levels

- Vitamin $D$ is seasonal and cannot be made during the winter-time while the amount in summer time is subject to sunshine, weather and other factors

\section{What are the rates of deficiency in older adults in Ireland ${ }^{* 1}$ ?}

- $47 \%$ of all adults aged $>85$ are deficient in winter $(31,480)$

- $27 \%$ of the over 70 s who are 'cocooning' are likely to be deficient $(115,536)$

- 1 in $8(13 \%)$ adults over 55 are deficient $(149,049)$ all year

\section{Who is at risk of Vitamin D deficiency in Ireland?}

- People who are housebound/confined, little sun exposure and/or eat inadequate amounts of fortified foods

- People who don't take vitamin D supplements - currently over $91 \%$ of older adults $55+$ do not take a supplement during the winter $(1,038,752)$. Only $4 \%$ of men and $15 \%$ of women take a supplement

- People who are obese, physically inactive, have asthma or chronic lung disease

\section{Where is vitamin $D$ found}

- Vitamin D is made in the skin from 10-15 minutes per day of sun exposure - in Ireland only made from late March to late September

- Vitamin $D$ is available in oily fish (salmon, mackerel etc.), eggs, liver, fortified foods such as cereals and dairy products

\section{How much vitamin D should be taken to prevent deficiency?}

- $10 \mathrm{ug}(400 \mathrm{IU})$ is the minimum recommended daily during the winter time

- Between 15 -20 ug (800-1,000 IU/day) recommended for most at risk groups

1 For further information see: Laird E, O'Halloran AM, Carey D, Healy M, O'Connor D, Moore P, Shannon T, Molloy AM, Kenny RA. The prevalence of vitamin D deficiency and the determinants of 25 $(\mathrm{OH}) \mathrm{D}$ concentration in older Irish adults: Data from The Irish Longitudinal Study on Ageing (TILDA). The Journals of Gerontology: Series A. 2018 73(4):519-525. https://academic.oup.com/biomedgerontology/ article/73/4/519/4103040 


\section{Introduction}

In this report, we aim to describe the importance of vitamin D for immune function, the prevalence of vitamin $D$ deficiency and vitamin $D$ supplement use in Ireland by age group, gender, geographic location and by obesity and lung disease (particularly vulnerable to COVID-19), describe those most at risk of deficiency and the best sources of vitamin $D$ and recommendations to improve status. By compiling this report, we hope the information given can help in the mitigation of the negative health consequences of COVID-19.

\subsection{Vitamin D and immune function}

Vitamin $\mathrm{D}$ is essential for older adults to help maintain bone and muscle health, plays a key role in the prevention and the treatment of falls and fractures and helps the absorption of calcium from the gut (2). Recent research has also highlighted that it may have an important function within the immune system (3). With increased age, there is a shift in the immune response to a more pro-inflammatory state which may lead to chronic low level inflammation and a slow accumulation of damage, with subsequent progression to chronic disease. This age related pro-inflammatory state is referred to as 'inflamm-aging' (4). This can be particularly important in periods of metabolic stress such as infection - the body is already pre-set to a higher level of inflammation and the necessary immune response to the infection may be impaired. Experiments and research has shown that vitamin D can alter the immune system response through its influence on the production and manufacturing of immune molecules known as cytokines (5). Vitamin D has been shown to help signal the increased production of ant-inflammatory molecules and decrease the production of pro-inflammatory molecules $(6,7)$. This switch in immune response in theory may have some potential benefit in cases of 'cytokine storm' - a massive release of proinflammation (which has been observed in those infected with COVID (8)) which can cause acute respiratory distress syndrome (9). Importantly, in a large cross-sectional clinical trial $(n=18,883)$ the risk of respiratory infection increased with lower blood vitamin $D$ levels and the effect was even stronger in those with underlying lung conditions (10). Many casecontrol studies have also reported associations between low vitamin $D$ and increased risk of infection (11) while in a trial supplementing patients at risk of respiratory infection with 1,000 International units (IU) of vitamin D a day for a year, supplement use reduced both symptoms and antibiotic use (12). 
Recently, a large meta-analysis (data analysis of a large collection of previous studies) of 10,933 people from 25 trials conducted in 15 countries investigated whether taking a vitamin $D$ supplement helped to prevent colds, flu and chest infections (acute respiratory infections - ARIs) (13). Vitamin D had a significant protective effect when it was given daily or weekly to people with lowest vitamin D levels: the risk of having at least one ARI was reduced from $60 \%$ to $32 \%$ in these people. Overall, vitamin D supplements reduced the risk of having at least one ARI. The study authors concluded that taking a vitamin $D$ supplement was safe and can help protect against ARIs, particularly if baseline levels are low. In 2019, a newer analysis using 21,000 participants from across eight studies showed that those with a low blood vitamin $\mathrm{D}$ level had a $64 \%$ increased risk of communityacquired pneumonia (14).

Therefore, maintaining a sufficient vitamin D status in the adults is beneficial in prevention of ARI and may therefore be of benefit in the COVID-19 pandemic. 


\section{The TILDA Sample}

This report uses data collected in Wave 1 of The Irish Longitudinal Study on Ageing (TILDA), a prospective study of 8,172 community-dwelling adults aged 50 years and older in Ireland. Since 2009, TILDA has collected information about the health and social circumstances of older adults using a comprehensive Computer Assisted Personal Interview (CAPI) conducted by interviewers who visited the participants in their own homes. This included detailed questions on socio-demographics, physical, mental and behavioural health. Information recorded included gender, age, habitation (living alone yes/ no), currently smoking (yes/no), lung condition (yes/no), province of residence: (Leinster - East, Munster - South and the combined provinces of Ulster/Connacht - West/North) and household housing wealth (measure of economic resource "asset wealth" defined as above or below the average of 278,359 Euros). Medications taken on a daily basis including prescription, non-prescription and vitamin D supplements were also recorded. Self-reported physical activity levels were classified using the International Physical Activity Questionnaire (IPAQ) categories: physically active (minimally or health enhancing physically active) versus physically inactive (inactive or insufficiently active). Obesity was measured as a body mass index $(\mathrm{BMI})>30 \mathrm{~kg} / \mathrm{m} 2$.

Approximately $72.1 \%$ ( $n=5,895)$ of the study population consented to, and participated in, a health assessment. Of those, $91.3 \%(n=5,382)$ provided a blood sample for vitamin D (25-hydroxyvitamin $\mathrm{D}(25(\mathrm{OH}) \mathrm{D})$ measurement. In this report we use the internationally accepted definitions of vitamin D status: deficient (<30 nmol/L); insufficient (30 -50 nmol/L) and sufficient ( $>50 \mathrm{nmol} / \mathrm{L}$ ). Given that vitamin $\mathrm{D}$ is a seasonal vitamin, this had to be accounted for in any analysis of population prevalence. Thus, seasons were defined as winter (December-February), spring (March-May), summer (June-August), and autumn (September-November). Low and high vitamin D periods were defined as winter (with spring) and summer (with autumn), respectively.

\subsection{Statistical Methods and Weighting}

In this report, all TILDA prevalence estimates are weighted to account for age, sex, educational attainment and urban/rural residence in the 2011 Census (Wave 1 of TILDA collection). Prevalence estimates were also adjusted using modified base weights that accounted for survey non-response, non-attendance at the health assessment component of the study and whether or not respondents provided a blood sample. These weights 
and adjustments ensure that these estimates are representative of the whole population aged 50 years and over in Ireland. All of the calculated population estimates are then based on figures collected from the most recent 2016 Census data (which reported a total of $1,446,460$ people over 50 living in Ireland. It should be noted that the TILDA sampling frame does not include people with dementia at baseline or people living in nursing homes and as such this data may slightly underestimate prevalence for the total population in Ireland.

In light of the new HSE 'Guidance on cocooning to protect people over 70 years and those extremely medically vulnerable from COVID-19' (1) which came into effect from midnight on March 28th 2020, this report will also provide information in relation to vitamin D status in adults aged 70 years and over.

In light of the new HSE 'Guidance on coccooning to protect people over 70 years and those extremely medically vulnerable from COVID-19' which came into effect from midnight on March 28th 2020, this report will also provide information in relation to frailty on adults aged 70 and over. 


\section{Vitamin D Status of Older Adults in Ireland in Winter}

During the winter period, $21.3 \%(244,209)$ of adults aged $>55$ years were vitamin D deficient (Figure 1; Table 2). The highest rates of deficiency were observed for those aged $80-84$ years $(29.6 \% ; 23,987)$ and those aged $>85$ years $(46.6 \% ; 31,480)$. For those aged $>70$ years, the deficiency rates were $27.1 \%$ (115,536). Across all ages, deficiency rates were similar for both men and women though with men tending to have slightly higher deficiency rates overall.

Similar high rates of deficiency were observed when examined by province of residence (Figure 2; Table 3). Again, those aged $>85$ years had the highest rates of deficiency regardless of province. However, those aged $85+$ in the Connacht \& Ulster area had the highest deficiency rate $(59.5 \% ; 8,738)$. For those aged $>70$ years, the Munster region had the highest deficiency rate $(31.8 \% ; 39,410)$ vs the Leinster region $(21.4 \% ; 46,231)$. Overall, Leinster had the lowest rate of deficiency $(17.6 \% ; 103,615)$ compared to those residing in either Munster $(25.3 \% ; 83,615)$ or Connacht \& Ulster $(24.5 \% ; 55,690)$.

In winter, only $9.4 \%(107,773)$ of those aged $55+$ and $11.5 \%(49,028)$ of those aged $70+$ reported taking a vitamin $\mathrm{D}$ supplement (Table 4). A much higher proportion of women $(14.6 \% ; 87,181)$ compared to men $(3.8 \% ; 20,877)$ took a supplement. This sex difference was consistent when examined by age as for instance, in those aged $85+$ only $5.6 \%$ $(1,291)$ of men vs $17.7 \%(7,875)$ of women reported taking a supplement.. 


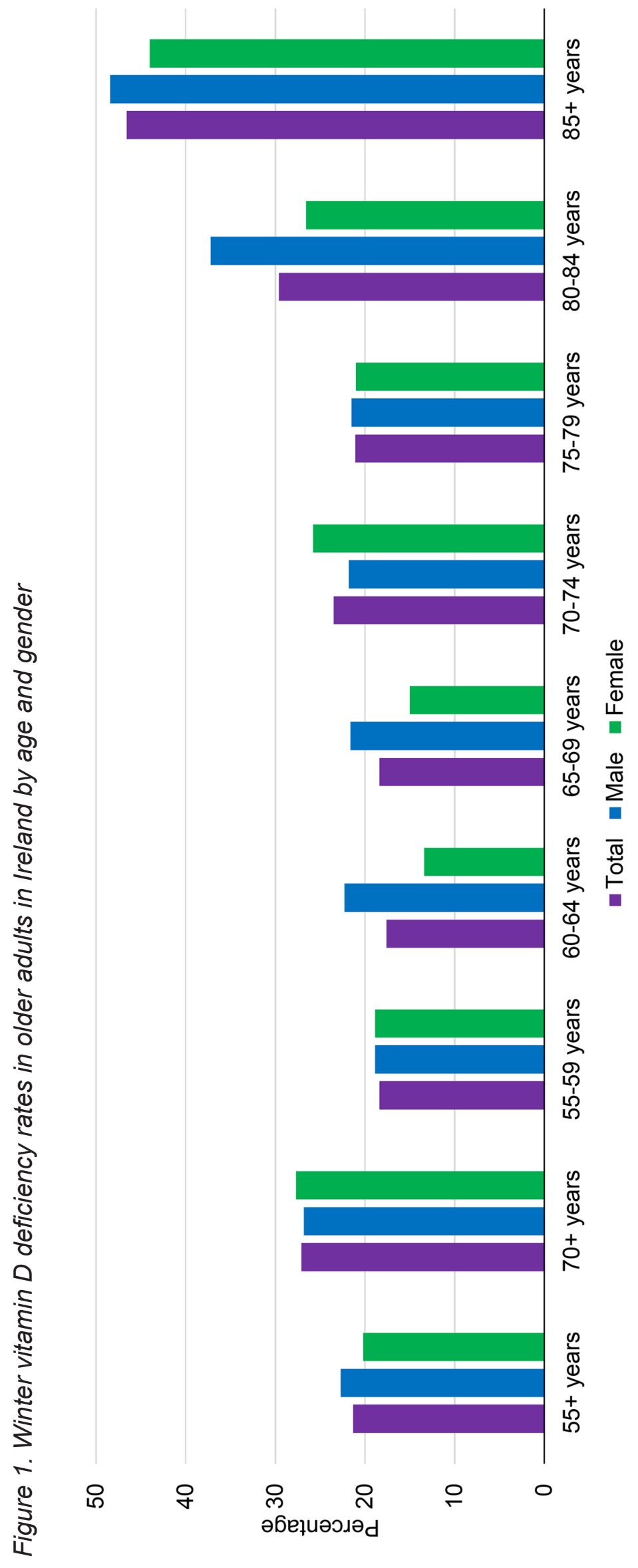




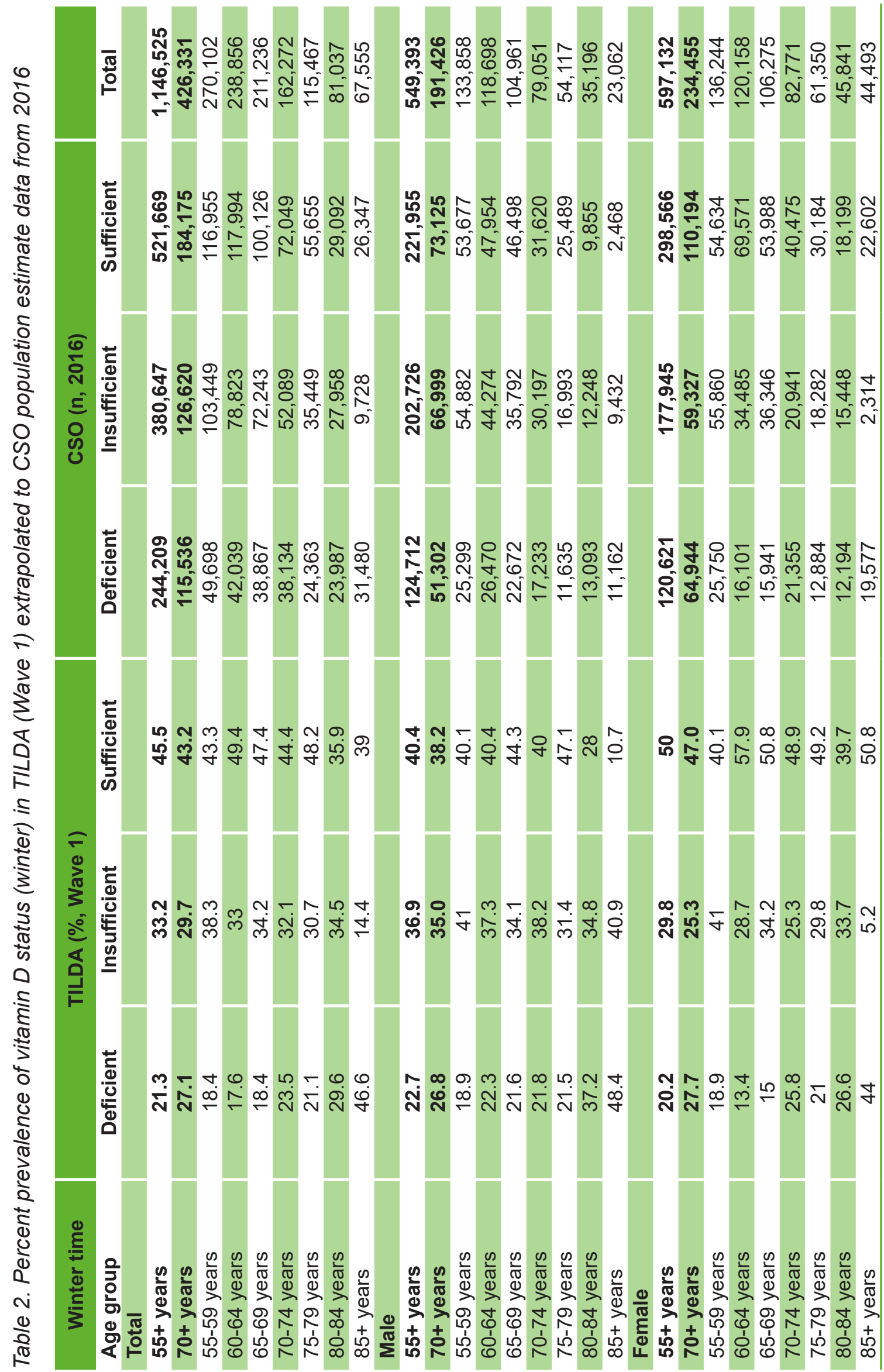




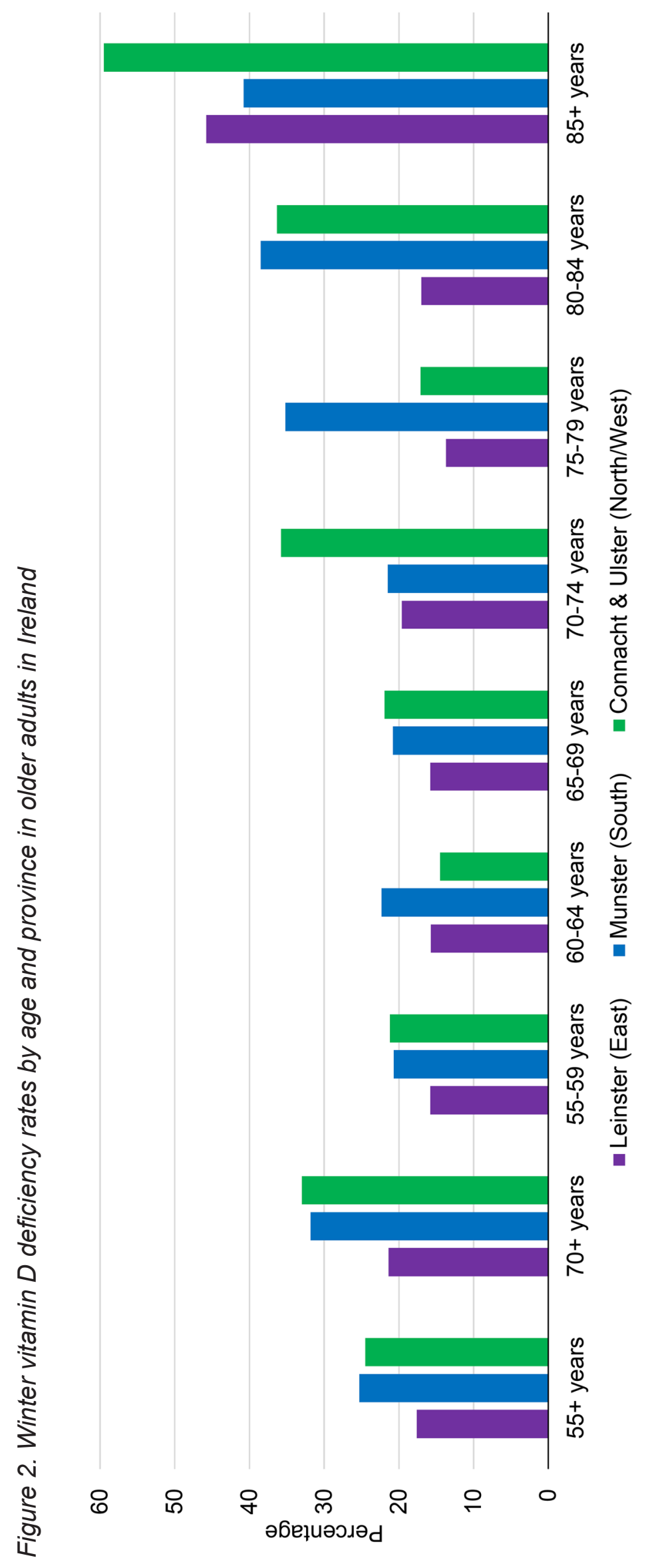


รับ กั

ஜ m. กิ

$\frac{0}{2}$

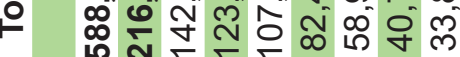

吕

อ

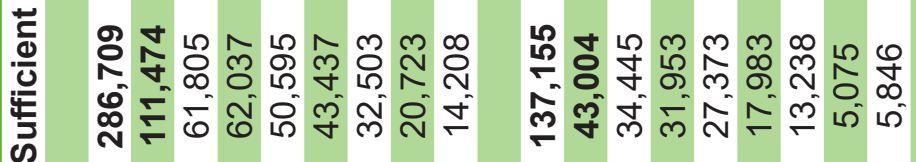

เ

๙ั

is

$\frac{8}{\frac{1}{2}}$

ㅇำ

\&

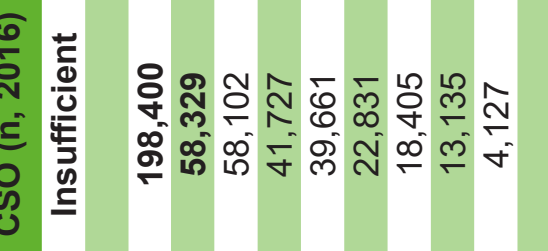

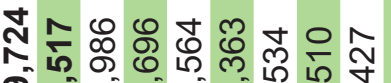

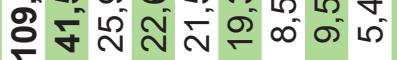

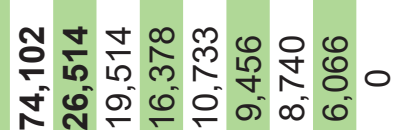

r)

$\stackrel{1}{1}$

$\sum_{1}^{2}$

Ð

.5

$\stackrel{\text { 离 }}{\stackrel{5}{5}}$

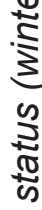

$\frac{\sqrt{7}}{\sqrt{2}}$

4

ป

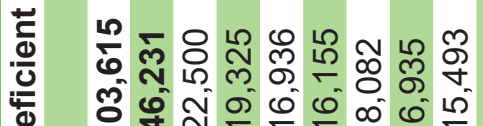

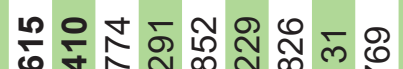

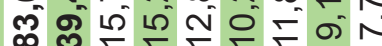

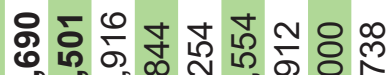

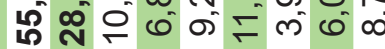
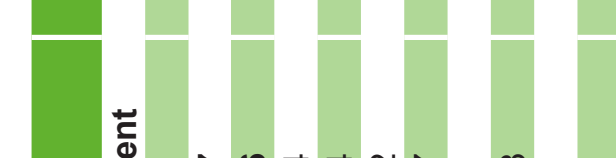

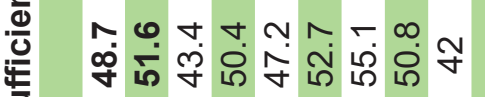

$\ln 2$ ᄂ 守

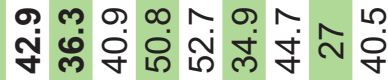

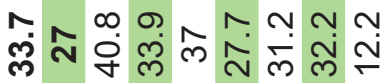

กั

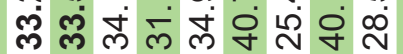

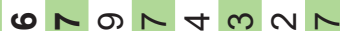
กู่

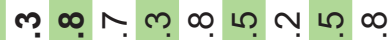

นึ่

每

$\stackrel{1}{2}$

2

ปัป

$\frac{0}{20}$

mi

$\frac{0}{\frac{1}{0}}$

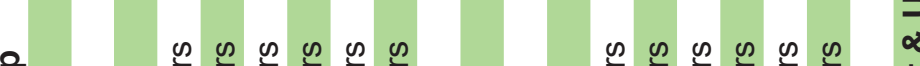


Table 4. Prevalence of vitamin D supplement use (winter) in TILDA (Wave 1) by province extrapolated to CSO population estimate data from 2016

\begin{tabular}{|c|c|c|c|c|c|}
\hline \multirow{2}{*}{$\begin{array}{l}\text { Winter time } \\
\text { Age group }\end{array}$} & \multicolumn{2}{|c|}{ TILDA (\%, Wave 1) } & \multicolumn{2}{|c|}{$\operatorname{CSO}(n, 2016)$} & \multirow[b]{2}{*}{ Total } \\
\hline & Yes & No & Yes & No & \\
\hline \multicolumn{6}{|l|}{ Total } \\
\hline $55+$ years & 9.4 & 90.6 & 107,773 & $1,038,752$ & $1,146,525$ \\
\hline $70+$ years & 11.5 & 88.5 & 49,028 & 377,303 & 426,331 \\
\hline $55-59$ years & 5.6 & 94.4 & 15,126 & 254,976 & 270,102 \\
\hline $60-64$ years & 9.6 & 90.4 & 22,930 & 215,926 & 238,856 \\
\hline $65-69$ years & 9.6 & 90.4 & 20,279 & 190,957 & 211,236 \\
\hline $70-74$ years & 11.5 & 88.5 & 18,661 & 143,611 & 162,272 \\
\hline $75-79$ years & 13.9 & 86.1 & 16,050 & 99,417 & 115,467 \\
\hline $80-84$ years & 7.6 & 92.4 & 6,159 & 74,878 & 81,037 \\
\hline $85+$ years & 13.5 & 86.5 & 9,120 & 58,435 & 67,555 \\
\hline \multicolumn{6}{|l|}{ Male } \\
\hline $55+$ years & 3.8 & 96.2 & 20,877 & 528,516 & 549,393 \\
\hline $70+$ years & 4.8 & 95.2 & 9,188 & 182,238 & 191,426 \\
\hline $55-59$ years & 2.2 & 97.8 & 2,945 & 130,913 & 133,858 \\
\hline $60-64$ years & 4.1 & 95.9 & 4,867 & 113,831 & 118,698 \\
\hline $65-69$ years & 3.6 & 96.4 & 3,779 & 101,182 & 104,961 \\
\hline $70-74$ years & 5.4 & 94.6 & 4,269 & 74,782 & 79,051 \\
\hline $75-79$ years & 5 & 95 & 2,706 & 51,411 & 54,117 \\
\hline $80-84$ years & 4.6 & 95.4 & 1,619 & 33,577 & 35,196 \\
\hline $85+$ years & 5.6 & 94.4 & 1,291 & 21,771 & 23,062 \\
\hline \multicolumn{6}{|l|}{ Female } \\
\hline $55+$ years & 14.6 & 85.4 & 87,181 & 509,951 & 597,132 \\
\hline $70+$ years & 16.7 & 83.3 & 39,151 & 195,284 & 234,435 \\
\hline $55-59$ years & 9.3 & 90.7 & 12,671 & 123,573 & 136,244 \\
\hline $60-64$ years & 15.1 & 84.9 & 18,144 & 102,014 & 120,158 \\
\hline $65-69$ years & 15.3 & 84.7 & 16,260 & 90,015 & 106,275 \\
\hline $70-74$ years & 17.8 & 82.2 & 14,733 & 68,038 & 82,771 \\
\hline $75-79$ years & 21.8 & 78.2 & 13,374 & 47,976 & 61,350 \\
\hline $80-84$ years & 9.2 & 90.8 & 4,217 & 41,624 & 45,841 \\
\hline $85+$ years & 17.7 & 82.3 & 7,875 & 36,618 & 44,493 \\
\hline
\end{tabular}




\section{Vitamin D Status of Older Adults in Ireland in Summer}

During the summer period (optimum period for making vitamin D from sunlight), $8.4 \%$ $(96,308)$ of adults aged $>55$ years were vitamin $D$ deficient (Figure 3 ; Table 5 ) while for those aged $70+$, the rate of deficiency was $12.1 \%(51,586)$. The highest rates of deficiency were observed for those aged $85+$ years $(30.7 \% ; 20,739)$. Similar age defined rates were observed for both men and women though with women having slightly higher deficiency rates overall.

Similar rates of deficiency were observed when examined by province of residence (Figure 4 ; Table 6 ). Again, those aged $>85$ years had the highest rates of deficiency regardless of province. However, those aged $85+$ in the Connacht \& Ulster area had the highest deficiency rate $(48.3 \% ; 7,093)$ followed by Munster area $(41.1 \% ; 7,826)$ and then Leinster $(20.7 \% ; 7,002)$. Overall, Leinster again had the lowest rate of deficiency $(6.8 \% ; 40,033)$ compared to those residing in either Munster $(9.5 \%$; 31,397$)$ or Connacht \& Ulster $(10.0 \%$; $22,731)$. For those aged $70+$, those residing in Munster had a deficiency rate of $15.9 \%$ $(19,705)$ vs $10.3 \%(22,252)$ in Leinster.

In summer, $10.3 \%(118,092)$ of those aged $55+$ reported taking a vitamin D supplement (Table 7). Again, a much higher proportion of women $(14.6 \% ; 87,181)$ compared to men $(5.5 \% ; 30,217)$ took a supplement. For those aged $70+$, only $14.2 \%(60,539)$ took a vitamin D supplement.

\subsection{Risk factors for deficiency}

The risk factors for vitamin D deficiency are displayed in Figure 5. The largest negative predictors included smoking, geographic location (living in the North and West compared to the East of the country), winter season, physically inactivity, and older age. The largest positive predictor of vitamin $D$ was vitamin $D$ supplement use followed by being female. 


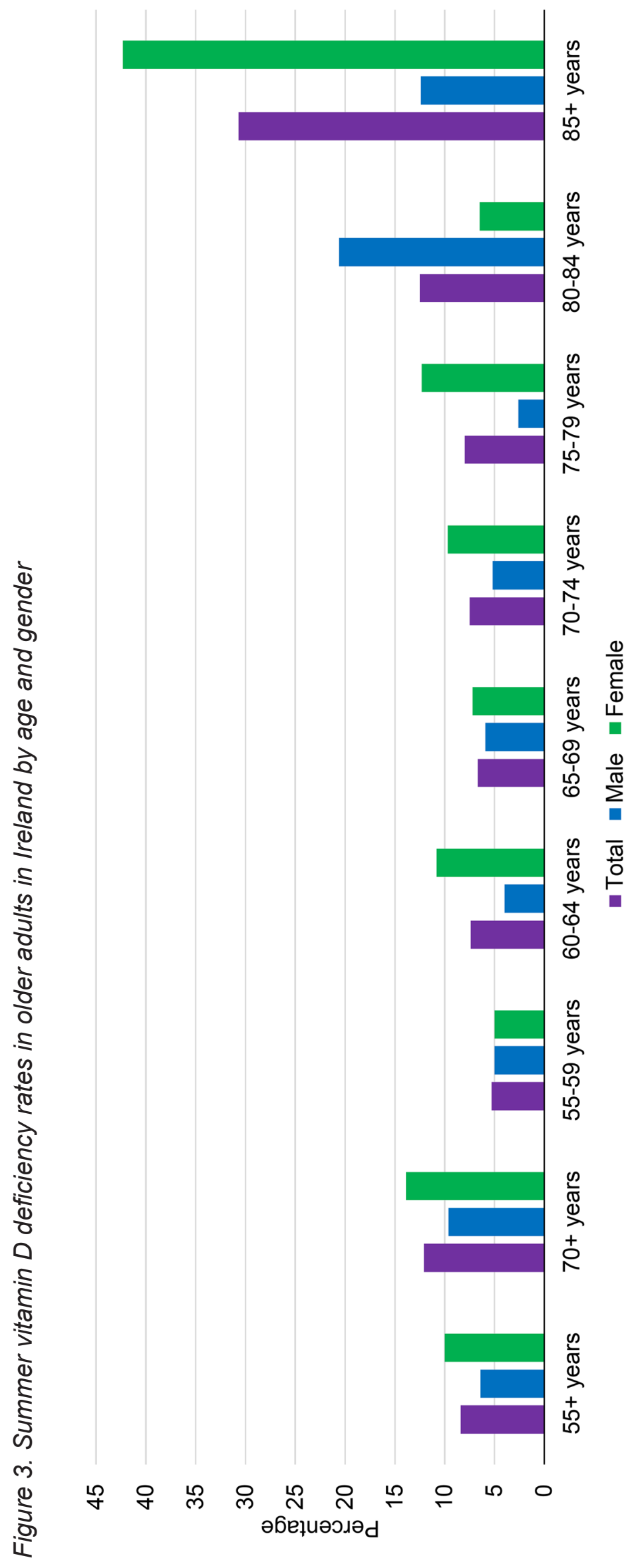




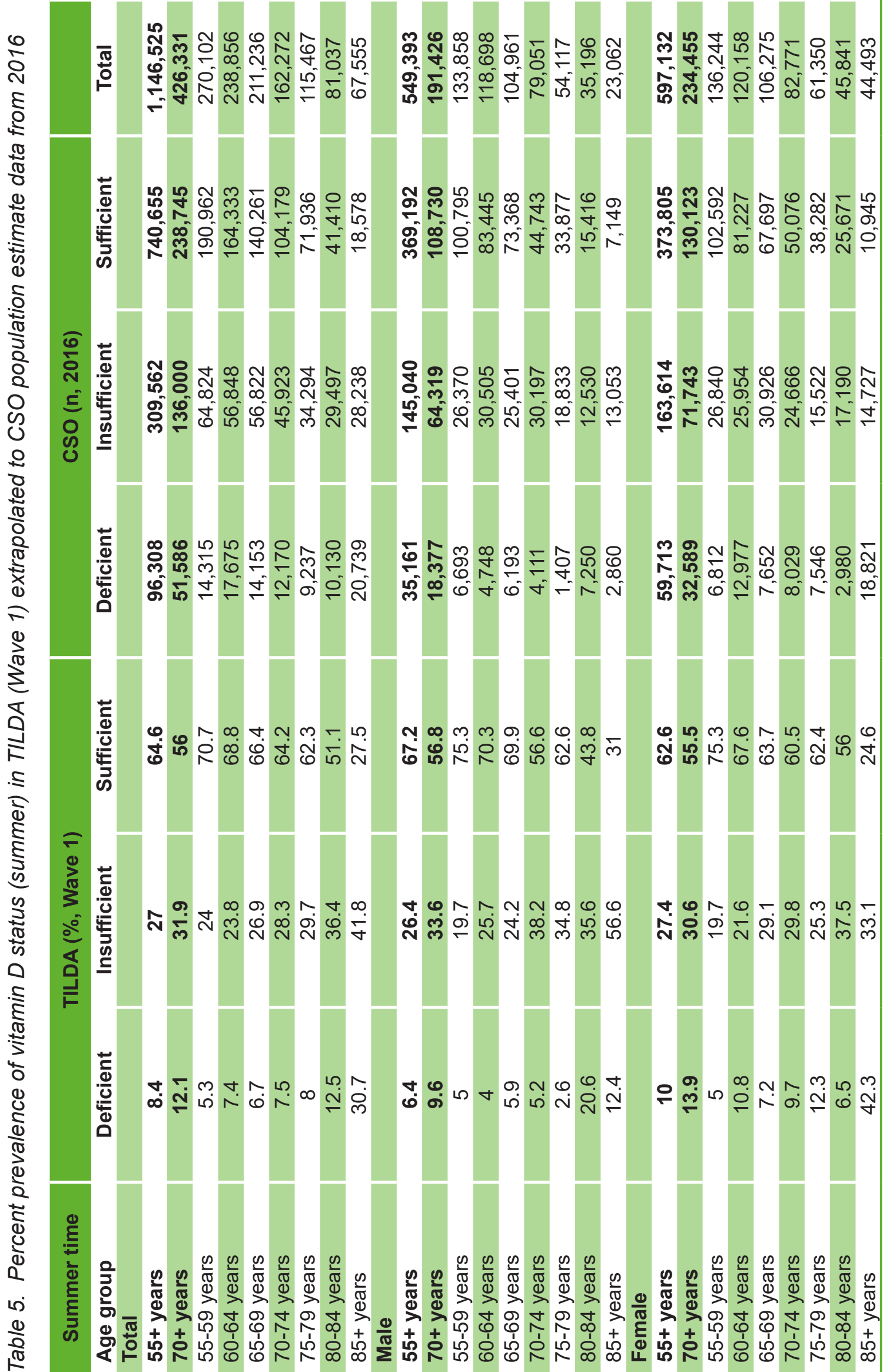




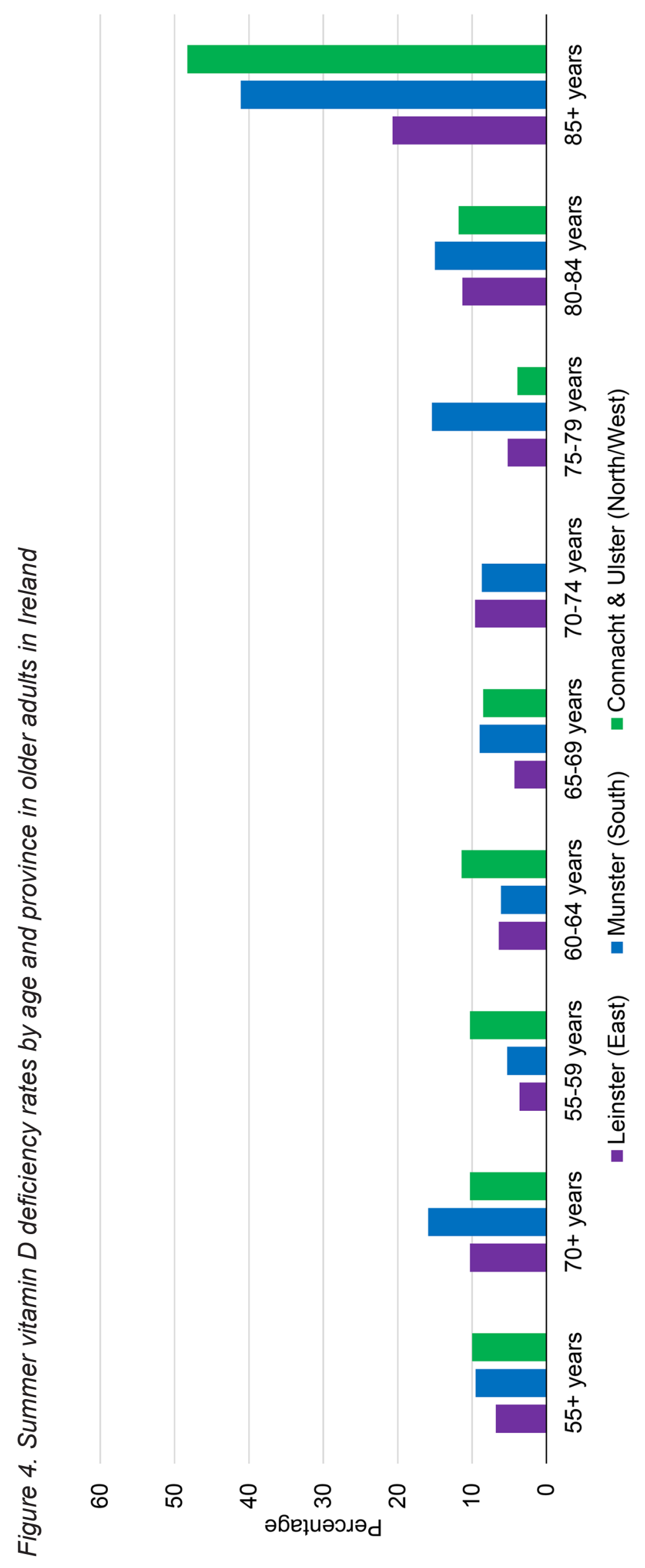


$+$

స

药

$\frac{0}{\frac{\pi}{2}}$

ह

高

$\frac{\pi}{2}$

ำ

บ

은

일

$\frac{\pi}{0}$

$\frac{\sqrt{2}}{\frac{0}{2}}$

장

ป

$\frac{2}{2}$

$\overrightarrow{2}$

₹

$\sum_{3}^{0}$

$\Sigma$

$\$$

근

.5

ఏ

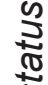

क

$\sqrt{\frac{2}{\Sigma}}$

4

ভ

$\frac{1}{\pi}$

ฮ)

ญु

mָำ

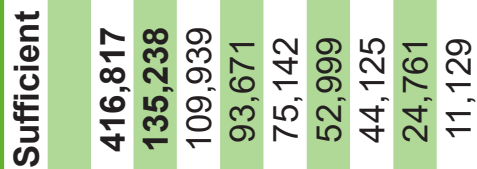

œ

๔

กิ ๆ

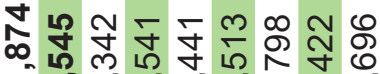

๓

잉드

ㅇํำ

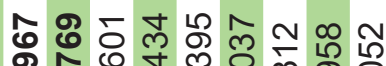

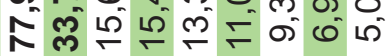

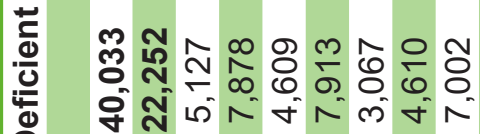

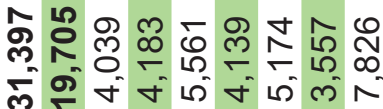

ஸ்

స

$\infty$

唡

$\sim \forall の \infty \downarrow-m$

ம

ฟั

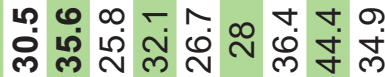

mँ

\section{m ल m}

$\infty m \omega+m \in \omega m$

مீ

0 c

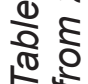
0 ¿ 4

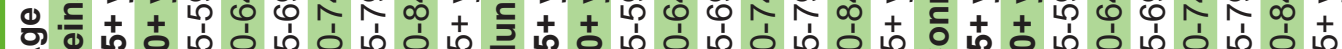

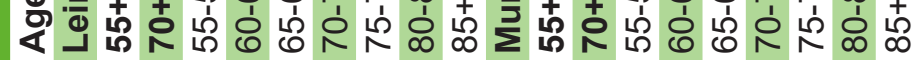

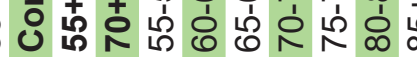


Table 7. Prevalence of vitamin D supplement use (summer) in TILDA (Wave 1) by province extrapolated to CSO population estimate data from 2016

\begin{tabular}{|c|c|c|c|c|c|}
\hline \multirow{2}{*}{$\begin{array}{l}\text { Summer time } \\
\text { Age group }\end{array}$} & \multicolumn{2}{|c|}{ TILDA (\%, Wave 1) } & \multicolumn{2}{|c|}{$\operatorname{csO}(n, 2016)$} & \multirow[b]{2}{*}{ Total } \\
\hline & Yes & No & Yes & No & \\
\hline \multicolumn{6}{|l|}{ Total } \\
\hline $55+$ years & 10.3 & 89.7 & 118,092 & $1,028,433$ & $1,146,525$ \\
\hline $70+$ years & 14.2 & 85.8 & 60,539 & 365,792 & 426,331 \\
\hline $55-59$ years & 7.3 & 92.7 & 19,717 & 250,385 & 270,102 \\
\hline $60-64$ years & 8.6 & 91.4 & 20,542 & 218,314 & 238,856 \\
\hline $65-69$ years & 9 & 91 & 19,011 & 192,225 & 211,236 \\
\hline 70-74 years & 14 & 86 & 2,272 & 139,554 & 162,272 \\
\hline $75-79$ years & 10.2 & 89.8 & 11,778 & 103,689 & 115,467 \\
\hline 80-84 years & 21.2 & 78.8 & 17,180 & 63,857 & 81,037 \\
\hline $85+$ years & 10.1 & 89.9 & 6,823 & 60,732 & 67,555 \\
\hline \multicolumn{6}{|l|}{ Male } \\
\hline $55+$ years & 5.5 & 5.5 & 30,217 & 519,176 & 549,393 \\
\hline $70+$ years & 9.1 & 90.9 & 17,420 & 174,006 & 191,426 \\
\hline $55-59$ years & 3.9 & 3.9 & 5,220 & 128,638 & 133,858 \\
\hline $60-64$ years & 3.7 & 3.7 & 4,392 & 114,306 & 118,698 \\
\hline $65-69$ years & 3.7 & 3.7 & 3,884 & 101,077 & 104,961 \\
\hline $70-74$ years & 8.9 & 8.9 & 7,036 & 72,015 & 79,051 \\
\hline $75-79$ years & 4.8 & 4.8 & 25,976 & 51,519 & 54,117 \\
\hline 80-84 years & 11.5 & 11.5 & 4,048 & 31,148 & 35,196 \\
\hline $85+$ years & 16.7 & 16.7 & 3,851 & 19,211 & 23,062 \\
\hline \multicolumn{6}{|l|}{ Female } \\
\hline $55+$ years & 14.6 & 85.4 & 87,181 & 509,951 & 597,132 \\
\hline $70+$ years & 18.1 & 81.9 & 42,436 & 192,019 & 234,455 \\
\hline $55-59$ years & 10 & 90 & 13,624 & 122,620 & 136,244 \\
\hline $60-64$ years & 13.4 & 86.6 & 16,101 & 104,057 & 120,158 \\
\hline $65-69$ years & 14.2 & 85.8 & 15,091 & 91,184 & 106,275 \\
\hline $70-74$ years & 18.2 & 81.8 & 15,064 & 67,707 & 82,771 \\
\hline $75-79$ years & 14.7 & 85.3 & 9,018 & 52,332 & 61,350 \\
\hline $80-84$ years & 28.2 & 71.8 & 12,927 & 32,914 & 45,841 \\
\hline $85+$ years & 6.4 & 93.6 & 2,848 & 41,645 & 44,493 \\
\hline
\end{tabular}


Figure 5. Factors which can influence blood vitamin D levels in older Irish adults

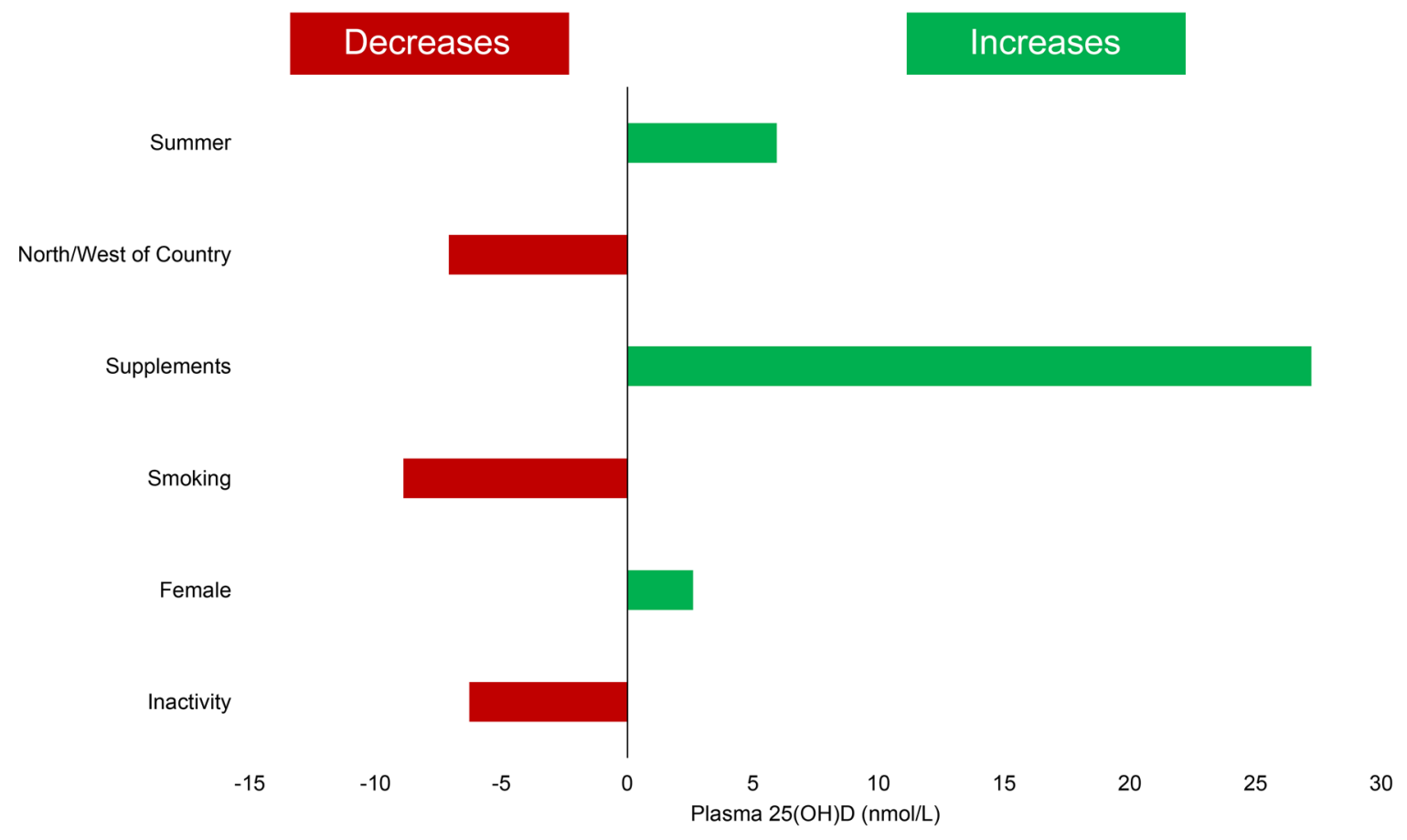




\section{Vitamin D status by obesity and respiratory lung conditions}

Overall, obese older adults had much higher rates of vitamin D deficiency both in winter and summer (Figures 6-7). During winter, rates of vitamin D deficiency in the obese were $27.3 \%$ for those aged $55+$ and $35.3 \%$ for those aged $70+$ compared to $20.8 \%$ and $27.0 \%$ respectively for those not obese. Similar trends were also observed during summer.

In those reporting chronic lung disease (such as chronic bronchitis or emphysema), the prevalence of vitamin $D$ deficiency was significantly higher than those not reporting disease across the age groups both in winter and summer (Figures 8-9). For instance in those aged $>55$ years, the prevalence in winter of deficiency was $33.8 \%$ in those with lung conditions vs $22.7 \%$ with no conditions. Similar trends were observed in $70+$ age group where rates were 32 vs $29.9 \%$ in winter and 16.9 vs $12.3 \%$ in summer 


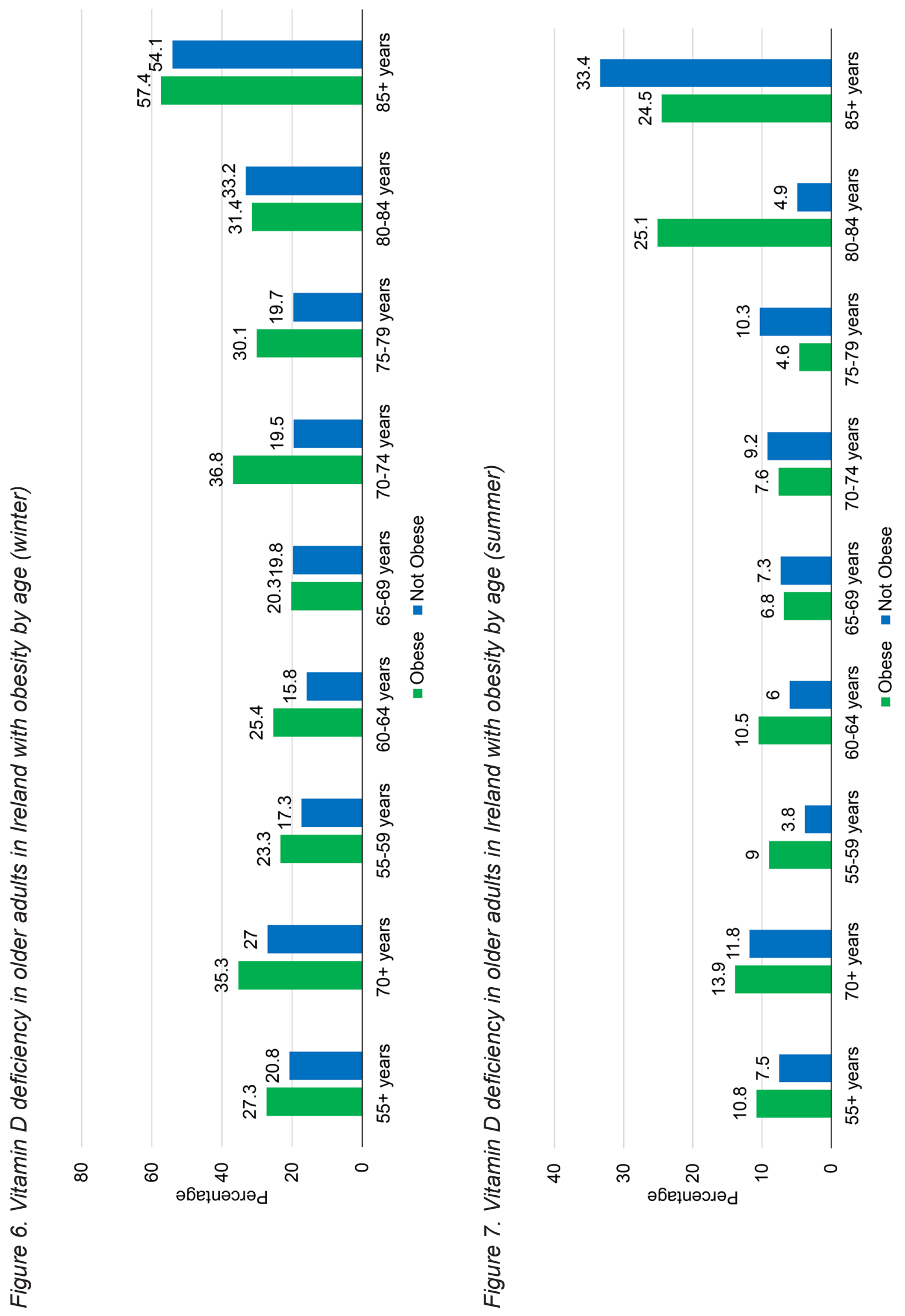




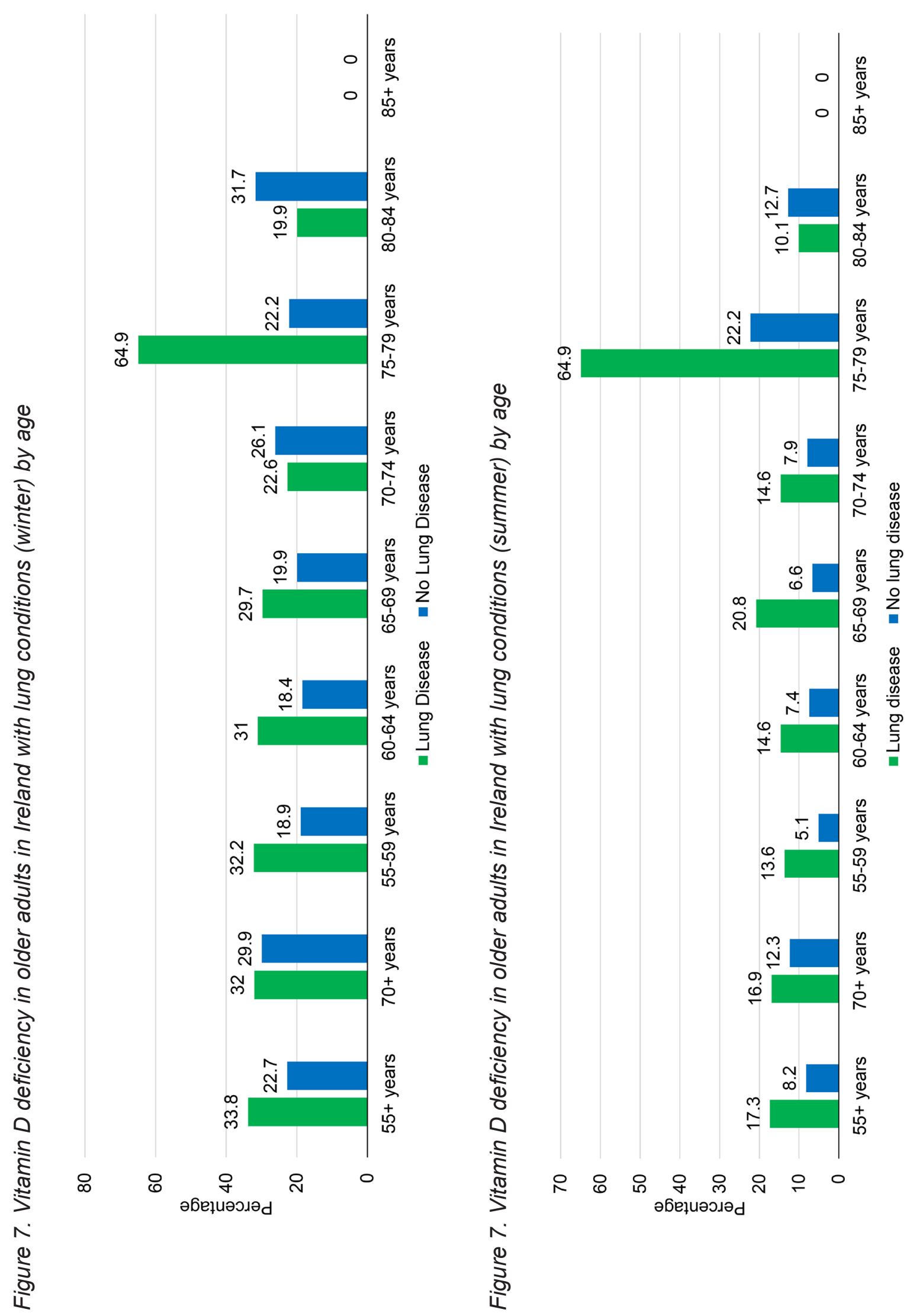




\section{Discussion}

This report demonstrates that of those aged 55+ years in Rep. of Ireland, 1 in 5 are vitamin $\mathrm{D}$ deficient during the winter and 1 in 12 during the summer. Of particular concern is that nearly $30 \%$ of those aged $70+$ and $47 \%$ of those aged $85+$ are deficient in vitamin D. These are the age groups who are considered to be 'extremely medically vulnerable' to the adverse health outcomes of COVID-19 and have been advised to participate in 'cocooning' during the COVID-19 public health emergency. Of extra concern is the fact that only $10.5 \%$ of those aged $70+$ actually report taking a vitamin D supplement - because of 'cocooning' many may now lack the opportunity for sun exposure and given the low use of supplements, many of this vulnerable group could be at very high risk of deficiency. This of key importance given the usefulness of vitamin $D$ for immune function particularly at this time.

Of particular concern we have observed very high levels of vitamin D deficiency in those who are obese and those with pre-existing lung conditions both of which have been observed to make individuals particularly vulnerable to COVID-19 and complications from the virus $(15,16)$.

Ireland does not have any formal vitamin D food policy - we practice a voluntary but not mandatory food fortification policy where food manufacturers can decide to fortify (or not) their food products with vitamin D. The vitamin D status of those in Ireland is lower than either the United States or Canada who have systematic (mass) vitamin D food fortification. However, vitamin D deficiency is not inevitable in older adults in Ireland and the ability to have sufficient vitamin D status year round is an achievable goal that many countries meet. For example, another European country - Finland (which is at a much higher latitude and therefore receives less sunshine than Ireland) has virtually eliminated vitamin $D$ deficiency in its population with rates $<1 \%(17)$. This is due in part to a successful food fortification and vitamin D supplement policy and educating the public and medical practitioners on the importance of vitamin $D$. This vitamin $D$ success story demonstrates what could be achieved in Ireland. 


\section{Here we outline the main sources of vitamin D and what are the intake recommendations}

\section{Vitamin D sources}

There are three main sources of vitamin D - sunlight, food and supplements. Due to Ireland's far latitude geographic location, vitamin D synthesis by sunlight is only during the months of late March to late September. This is 10-15 minutes exposure to sunlight (before application with sun-protection at a time period between 12-4 pm). However, even during the summer, the amount of vitamin $D$ that can be made is affected by cloud cover, use of skin creams, clothing, obesity and age (18). Foods rich in this micronutrient include oily fish (tinned or fresh salmon, mackerel etc.), egg yolks, liver and vitamin D fortified foods such as cereals and dairy products (Appendix 1). Regular consumption of vitamin D rich foods is recommended to help prevent deficiency, particularly in the winter months and those not exposed to sunshine in the summer time.

\section{Vitamin D Intake recommendations}

During the winter-period at least $10 \mathrm{ug} /$ day $(400 \mathrm{IU})$ from the diet is required (due to the lack of sunlight for vitamin D synthesis). Recent data has shown that the average intakes from diet are significantly below this level and therefore a $10 \mathrm{ug}$ (400 IU) vitamin D supplement maybe be required during the winter. For those who are housebound (due to illness or quarantine for an extended period) an upper supplement of 15-20 ug/day (600$800 \mathrm{IU})$ maybe required due to the lack of sunshine exposure. In persons over 70 years, 20-25 ug/day (800-100IU) is recommended.

\subsection{Conclusion}

Our people aged 70 and over are the fabric of our society (19) and we must use all available tools to facilitate the reduction and transmission of COVD-19. Vitamin D is a potent immune modifying micronutrient and if vitamin $\mathrm{D}$ status is sufficient, it could benefit vulnerable adults in particular those $70+$ years and older who are 'cocooning' during the COVID-19 outbreak. 


\section{References}

1. Guidance on cocooning to protect people over 70 years and those extremely medically vulnerable from COVID-19. Health Service Executive (HSE), Republic of Ireland.

27 March 2020. https://www.hpsc.ie/az/respiratory/coronavirus/novelcoronavirus/ guidance/vulnerablegroupsguidance/COVID-19\%20Guidance $\% 20$ for $\% 20$

extremely\%20medically\%20vulnerable\%20V1.pdf

2. Committee to Review Dietary Reference Intakes for Vitamin D and Calcium, Institute of Medicine. Dietary Reference Intakes for Calcium and Vitamin D. Washington, DC: The National Academies Press; 2011.

3. Vanherwegen AS, Gysemans C, Mathieu. Regulation of immune function by vitamin D and its use in diseases of immunity. Endocrinol Metab Clin. 2017;46:1061-1094.

4. Ferrucci L, Fabbri E. Inflammageing: chronic inflammation in ageing, cardiovascular disease, and frailty. Nat Rev Cardiol. 2018; 15(9):505-522.

5. Di Rosa M, Malaguarnera M, Nicoletti F, Malaguarnera L. Vitamin D3: a helpful immuno-modulator. Immunology. 2011;134:123-139.

6. Laird E, McNulty H, Ward M, Hoey L, McSorley E, Wallace JM, et al. Vitamin D deficiency is associated with inflammation in older Irish adults. J Clin Endocrinol Metab. 2014;99(5):1807-1815.

7. Sloka S, Silva C, Wang J, Yong VW. Predominance of Th2 polarization by vitamin D through a STAT6-dependent mechanism. J Neuroinflammation. 2011;8(1):56.

8. Huang C, Wang Y, Li X, Ren L, Zhao J, Hu Y, et al. Clinical features of patients infected with 2019 novel coronavirus in Wuhan, China. The Lancet. 2020;395(10223):497-506

9. Xu Z, Shi L, Wang Y, Zhang J, Huang L, Zhang C, et al. Pathological findings of COVID-19 associated with acute respiratory distress syndrome. The Lancet respiratory medicine. 2020 Feb 18. 
10. Ginde AA, Mansbach JM, Camargo CA. Association between serum 25-hydroxyvitamin $D$ level and upper respiratory tract infection in the Third National Health and Nutrition Examination Survey. Arch Intern Med. 2009;169:384-390.

11. Jolliffe DA, Griffiths CJ, Martineau AR. Vitamin D in the prevention of acute respiratory infection: Systematic review of clinical studies. J Steroid Biochem Mol Biol. 2013;136:321-329.

12. Bergman P, Norlin AC, Hansen S, Rekha RS, Agerberth B, Björkhem-Bergman L, et al. Vitamin D3 supplementation in patients with frequent respiratory tract infections: a randomised and double-blind intervention study. BMJ Open. 2012;2(6):e001663.

13. Martineau AR, Jolliffe DA, Hooper RL, Greenberg L, Aloia JF, Bergman P, et al. Vitamin D supplementation to prevent acute respiratory tract infections: systematic review and meta-analysis of individual participant data. BMJ. 2017;356:i6583.

14. Zhou YF, Luo BA, Qin LL. The association between vitamin D deficiency and community-acquired pneumonia: A meta-analysis of observational studies. Medicine (Baltimore). 2019;98:e17252.

15. Jia X, Yin C, Lu S, Chen Y, Liu Q, Bai J, Lu Y. Two Things about COVID-19 Might Need Attention. Preprints. 2020, 2020020315 (doi: 10.20944/preprints202002.0315.v1)

16. Thornton J. Don't forget chronic lung and immune conditions during covid-19, says WHO. BMJ. 2020;368:m1192

17. Jääskeläinen $T$, Itkonen $S T$, Lundqvist $A$, Erkkola $M$, Koskela $T$, Lakkala $K$, et I. The positive impact of general vitamin $D$ food fortification policy on vitamin $D$ status in a representative adult Finnish population: evidence from an 11-y follow-up based on standardized 25-hydroxyvitamin D data. AJCN. 2017;105(6):1512-20

18. Laird E, Ward M, McSorley E, Strain JJ, Wallace J. Vitamin D and bone health; Potential mechanisms. Nutrients. 2010;2(7):693-724.

19. McGarrigle CA, Ward M, Scarlett S, Kenny RA. (2020) THE CONTRIBUTIONS OF THE OVER 70S TO IRISH SOCIETY: RESULTS FROM WAVE 5 OF THE IRISH LONGITUDINAL STUDY ON AGEING. https://www.doi.org/10.38018/TildaRe.2020-01 


\section{Appendix}

Appendix Table 1. Common dietary sources of vitamin $D$

\begin{tabular}{|l|c|c|c|}
\hline Dietary source & Quantity & Vitamin D $(\mu \mathrm{g})^{*}$ & Vitamin D (IU) \\
\hline Egg & 1 egg & 1.6 & 64 \\
\hline Liver (lamb) & $100 \mathrm{~g}$ & 0.9 & 36 \\
\hline Kidney (Lamb) & $100 \mathrm{~g}$ & 0.6 & 24 \\
\hline Salmon & $140 \mathrm{~g}$ & 10.2 & 408 \\
\hline Mackerel & $140 \mathrm{~g}$ & 11.9 & 476 \\
\hline Sardines (canned in oil) & $100 \mathrm{~g}$ & 5 & 200 \\
\hline Fortified milks & $200 \mathrm{ml}$ (glass) & 4 & 160 \\
\hline Fortified cereals & $35 \mathrm{~g}$ & 2.94 & 117.6 \\
\hline
\end{tabular}

*10ug or $400 \mathrm{IU}$ per day suggested requirements

Appendix Table 2. Factors that can influence vitamin D status

\begin{tabular}{|l|l|l|}
\hline & Reason & Notes \\
\hline $\mathbf{1}$ & Geographic location & Far latitude countries most at risk \\
\hline $\mathbf{2}$ & Season (Winter vs Summer) & Majority of vitamin D is made in Summer \\
\hline $\mathbf{3}$ & Low sun exposure & Due to sun-cream, clothing or skin pigmentation \\
\hline $\mathbf{4}$ & Age & Older age, infants and pregnant women at risk \\
\hline $\mathbf{5}$ & Obesity & BMI $>\mathbf{2 5} \mathrm{kg} / \mathrm{m} 2$ at risk \\
\hline $\mathbf{6}$ & Smoking & Sustainably increased risk of deficiency \\
\hline $\mathbf{7}$ & Poverty & Can result in low sun exposure (holidays) or poor diet \\
\hline $\mathbf{8}$ & Poor diet & Low intakes of oily fish, eggs, fortified foods \\
\hline $\mathbf{9}$ & Malabsorption syndromes & This can include Coeliac, Crohn's etc. \\
\hline $\mathbf{1 0}$ & Genetic conditions & Can result in lower blood vitamin D \\
\hline
\end{tabular}

